Natural Hazards and Earth System Sciences (2003) 3: 179-195

(C) European Geosciences Union 2003

Natural Hazards and Earth System Sciences

\title{
Distributed power-law seismicity changes and crustal deformation in the SW Hellenic ARC
}

\author{
A. Tzanis ${ }^{1}$ and F. Vallianatos ${ }^{2}$ \\ ${ }^{1}$ Department of Geophysics and Geothermy, University of Athens, Panepistimiopoli, 15784 Zografou, Greece \\ ${ }^{2}$ Department of Natural Resources Engineering, Technological Educational Institute of Crete, Chania Branch, Crete, Greece
}

Received: 27 June 2002 - Revised: 7 November 2002 - Accepted: 20 November 2002

\begin{abstract}
A region of definite accelerating seismic release rates has been identified at the SW Hellenic Arc and Trench system, of Peloponnesus, and to the south-west of the island of Kythera (Greece). The identification was made after detailed, parametric time-to-failure modelling on a $0.1^{\circ}$ square grid over the area $20^{\circ} \mathrm{E}-27^{\circ} \mathrm{E}$ and $34^{\circ} \mathrm{N}-38^{\circ} \mathrm{N}$. The observations are strongly suggestive of terminal-stage critical point behaviour (critical exponent of the order of 0.25 ), leading to a large earthquake with magnitude $7.1 \pm 0.4$, to occur at time $2003.6 \pm 0.6$. In addition to the region of accelerating seismic release rates, an adjacent region of decelerating seismicity was also observed. The acceleration/deceleration pattern appears in such a well structured and organised manner, which is strongly suggestive of a causal relationship. An explanation may be that the observed characteristics of distributed power-law seismicity changes may be produced by stress transfer from a fault, to a region already subjected to stress inhomogeneities, i.e. a region defined by the stress field required to rupture a fault with a specified size, orientation and rake. Around a fault that is going to rupture, there are bright spots (regions of increasing stress) and stress shadows (regions relaxing stress); whereas acceleration may be observed in bright spots, deceleration may be expected in the shadows. We concluded that the observed seismic release patterns can possibly be explained with a family of NE-SW oriented, left-lateral, strike-slip to oblique-slip faults, located to the SW of Kythera and Antikythera and capable of producing earthquakes with magnitudes $M_{S} \sim 7$. Time-to-failure modelling and empirical analysis of earthquakes in the stress bright spots yield a critical exponent of the order 0.25 as expected from theory, and a predicted magnitude and critical time perfectly consistent with the figures given above. Although we have determined an approximate location, time and magnitude, it is as yet difficult to assert a prediction for reasons discussed in the text. However, our results, as well as similar independent observations by another research team,
\end{abstract}

Correspondence to: A. Tzanis

(atzanis@geol.uoa.gr) indicate that a strong earthquake may occur at the SW Hellenic Arc, in the next few years.

\section{Introduction}

\subsection{The critical point earthquake model}

During the past decade it has been credibly argued that rupture in heterogeneous media is a critical phenomenon (Herrmann and Roux, 1990; Vanneste and Sornette, 1992; Sornette et al., 1992), while a mounting body of evidence indicates that the earthquake generation process can be viewed as a critical phenomenon culminating with a large event that corresponds to some critical point (Keilis-Borok, 1990; Allgre and LeMouël, 1994; Sornette and Sammis, 1995; Saleur et al., 1996a, 1996b; Bowman et al., 1998; Rundle et al., 2000 and many others). According to the Critical Point (CP) earthquake hypothesis, failure in the crust can be thought of as a scaling up process in which failure at one scale of a fault network is part of the damage accumulation over a larger scale, leading to long range stress-stress correlation and an increase (acceleration) of seismic release rates prior to a large earthquake. The culminating large event will only occur when the network is in a critical state, balancing at the verge of disorder and characterised by both extreme susceptibility to external factors and strong correlation between its different parts.

Such a process may be described by a power-law time-tofailure relation of the form

$\sum \Omega(t)=K+A \cdot\left(t_{c}-t\right)^{n}$,

where $\Omega$ is any quantity estimated from the earthquake magnitude using an expression of the form

$\log _{10} \Omega=c \cdot M+d$.

$\sum \Omega(t)$ is the cumulative seismic release, $t_{c}$ is the critical time at which a critical state is attained, $K=\sum \Omega\left(t=t_{c}\right)$, 
$A$ is negative and $n<1$. This scaling law has been justified in terms of run-away crack propagation and empirical expressions for accelerating (tertiary) creep preceding failure in the laboratory (Voight, 1989; Varnes, 1989; Bufe and Varnes, 1993), but it can also result naturally from the manybody interactions between small cracks forming before the impending rupture (Sornette and Sammis, 1995; Saleur et al., 1996a, 1996b; Bowman et al., 1998). In the latter, small and intermediate size events are associated with the increasing correlation length of the regional stress, while the culminating earthquake in the cycle represents the critical point occurring when the system is correlated over long ranges.

Depending on the coefficients $c$ and $d$ in Eq. (2), the seismic release rates can be moment or energy $(c=1.5)$, Benioff strain, (square root of energy, $c=0.75$ ), or event count $(c=0, d=1)$. Previous work has determined that the cumulative Benioff strain is particularly useful when smaller events are also of interest and magnitude scaling is desirable, while cumulative moment is dominated by the larger earthquakes and event count does not allow for magnitude scaling. In that case (1) reads

$$
\varepsilon(t)=\sum_{i=1}^{N(t)} \sqrt{E_{i}(t)}=K+A\left(t_{c}-t\right)^{n},
$$

where $E_{i}(t)$ the energy of the $i^{t h}$ event and $N(t)$ is the total number of events at time $t$. Earlier work has empirically determined that typically, $n \approx 0.3$. There are also two theoretical predictions for the value of the critical exponent. Using a model seismogenic crust governed by a particular damage rheology, Ben-Zion and Lyakhovsky (2001) derive a non-singular power law relation for cumulative Benioff strain proportional to $\left(t_{c}-t\right)^{1 / 3}$, i.e. $n=1 / 3$. Rundle et al. (2000) adopt a very different approach by relating the behaviour of seismicity prior to a large earthquake to the excitation in proximity of a spinodal instability. They show that the power-law activation associated with the spinodal instability is essentially identical to the power-law acceleration of Benioff strain observed prior to earthquakes, and that $n=0.25$.

As Sammis and Sornette (2001) point out, the CP model is fundamentally different from the principle of Self-Organised Criticality, according to which earthquakes evolve spontaneously in a statistically stationary critical state of the Earth's crust. The SOC doctrine holds that all events belong to the same global population and participate in shaping the selforganized critical state. In this view earthquakes are inherently unpredictable, because any small spontaneous instability has a chance of cascading into a large earthquake. In the $\mathrm{CP}$ view however, a great earthquake represents the end of a cycle on its associated fault network and the beginning of a new one. The dynamic organization of the crust is not statistically stationary, but evolves as the cycle progresses and a great earthquake becomes more probable, thereby rendering possible the prediction of the cycle's end by monitoring the approach of the fault network toward a critical state.

The CP doctrine is concisely given by Sammis and Sornette (2001) as follows: (A) A large earthquake is only possi- ble when the crust has reached a critical state, because highly stressed patches must be correlated at the scale of the fault network if an event is to grow by rupturing through geometrical and rheological barriers. (B) A large earthquake moves parts of the network out of the critical state by destroying stress correlation and creating a "stress shadow". (C) Tectonic loading combined with stress transfer from smaller events re-establishes long range stress correlation, thus making the next large event possible. In this context, the CP model does not require the seismic cycle to be (quasi)periodic. Rather, the length of the cycle will depend of the evolution of stress-stress correlations, which may vary between cycles. Moreover, it does not necessitate that a large earthquake will occur when the system reaches the critical state; it only says that at this time, a large earthquake is possible. The exact time of this event may depend on several uncertain factors pertaining to the nucleation process, which may have significant time dependence (e.g. Dieterich, 1992). In short, the fundamental hypothesis is that following a large event, fault networks evolve from a stress deficit (shadow) back toward the critical state and that this can be monitored by observing regional seismicity. This simple property lends predictability to the $\mathrm{CP}$ model.

Previous work (Bufe and Varnes, 1993; Bufe et al., 1994; Saleur et al., 1996; Sornette and Sammis, 1995; Brehm and Braile, 1998, 1999; Bowman et al., 1998; Jaumé and Sykes, 1999; Papazachos and Papazachos, 2001) has developed and reviewed techniques to identify regions of accelerating seismicity and to attempt the prediction of the time and magnitude of the next large earthquake, sometimes with remarkable success. We note however that until recently, the CP model has been largely conceptual, based on the analogy with phase transitions and drawing support from theoretical simulations involving simple models, such as cellular automata. There have been no effective physical models to describe the observations and the evolution of the earthquake cycle. This situation changed in the last few years and more dependable models of regional seismicity with realistic fault geometry have been developed, that also show accelerating seismicity before large events.

Heimpel (1997) designed a model of heterogeneous faults interacting through elastic coupling and found the existence of irregular earthquake cycles developing in four stages, as predicted by the CP hypothesis. Specifically, they comprised relaxation following the main-shock of the previous cycle, self-organization with regional stress increase, criticality and a main shock associated with rapid stress drop. Using stress and earthquake histories simulated by a discrete fault with quenched heterogeneities in a 3-D elastic half space, BenZion and Lyakhovsky (2001) show that large model earthquakes are associated with non-repeating cyclical establishment and destruction of long-range stress correlations, accompanied by non-stationary cumulative Benioff strain release. Then, using a regional lithospheric model consisting of a seismogenic upper crust governed by the damage rheology of Lyakhovsky et al. (1997) over a viscoelastic substrate, the same authors demonstrate analytically for a sim- 
plified 1-D case that the employed damage rheology leads to a non-singular power law relation for cumulative Benioff strain proportional to $\left(t_{c}-t\right)^{1 / 3}$. The accelerated seismicity is found to be accommodated both by increasing rates of moderate events and increasing average event size.

An important observation of previous work has been that the size of the region of accelerating seismicity (the so-called "critical region") scales with the size of the culminating large event. On this basis, Bowman and King (2001) proposed that the observed characteristics of distributed accelerating seismicity can possibly be understood in terms of a model combining simple elastic rebound and static stress transfer, i.e. it is produced by a simple process of increasing tectonic stress in a region already subjected to stress inhomogeneities at all scale lengths. In a more thorough development of their argument, King and Bowman (2001) present a model based on the decay of the stress shadow from a previous large event. The stress shadow is relaxed linearly in time and fractal noise, representing local stress inhomogeneities, is added to the stress. Model earthquakes are calculated for those areas above a failure threshold. The process results in progressive increase of model event size and accelerated seismic release, in consequence of a corresponding increase in the number and size of patches above the failure threshold as the shadow decays. According to this model, the region of accelerating seismic release is associated with the region defined by the stress field required to rupture a fault with a specified orientation and rake. This is important in that it allows incorporating tectonic information into the analysis.

The work reviewed above suggests that static stress transfer to a fault network may result in earthquake triggering and many-fault interactions and hence to power-law acceleration of seismic release rates. There is now evidence that static stress changes may advance (retard) the time of large earthquakes and although the consensus from hitherto large scale observational studies is that both near and far field earthquake triggering is identified by periods of increased seismicity rates, there's no definitive information as to the rise and decay modes of such changes (for instance see Reasenberg and Simpson, 1992; Dieterich, 1994; Stein et al., 1997; Toda et al., 1998; Nalbant et al., 1998). The situation is aggravated in the case of far field triggering, where limited observational data exists, with contradictory (e.g. Hill et al., 1995; Jones and Haukson, 1997) or negative (e.g. Gomberg and Davis, 1996) results. We also note that there are published examples of observations neatly fitting into the CP model, i.e. observations of accelerating seismic release up to large events and stress shadows following them, that may be interpreted as evidence of seismic cycles representing the approach and retreat of a fault network from the critical state. In one of those, Harris and Simpson (1996) presented evidence for "Coulomb-stress shadows" following the 1857 Fort Tejon and the 1952 Kern County earthquakes. They found no $M>5.5$ events in the Coulomb-stress shadows for 50 years following the 1857 and 1952 events, while $M>5.5$ events continued at a normal rate in areas where the Coulomb stress was not lowered. Sammis and Sornette (2001) indicate that this is an expected consequence of the reduction in stress correlation length, associated with a retreat from the critical state following a large event. Analogous observations are repeated by Jones and Hauksson (1997) and discussed for the Landers earthquake as well, while an analysis of accelerating seismicity and stress accumulation for a respectable number of large Californian events by Bowman and King (2001), appears to lend great support to the idea.

In conclusion, there's ample theoretical and some observational evidence, that static stress transfer may drive powerlaw acceleration of seismic release rates. In this paper we present observational evidence from the SW Hellenic Arc that may provide additional constraints to the theoretical and modelling predictions reviewed above and, hopefully, information as to the nature of the physical processes involved. As will be seen, this evidence leads to conclusions tantamount to an intermediate term prediction of a large earthquake.

\subsection{The SW segment of the Hellenic Arc}

The SW segment of the Hellenic Arc $\left(34^{\circ} \mathrm{N}-37.5^{\circ} \mathrm{N}, 20^{\circ} \mathrm{E}\right.$ $-26^{\circ} \mathrm{E}$ ) is the most active plate margin of the Mediterranean area, with correspondingly high seismicity and relatively frequent occurrence of large earthquakes. The main geotectonic features of the area are shown in Fig. 1, the most dominant of which is the Hellenic Trench, where the eastern Mediterranean oceanic lithosphere (front part of the African plate) is subducted under the Aegean microplate. To the north of the trench, the Hellenic Arc (Peloponnesus - Kythera - Crete) comprises the accretionary prism and farther north, other typical elements of a subduction system are seen, namely the southern Aegean trough (Cretan Sea) and parts of the volcanic arc - Milos and Thera (Santorini).

As mentioned above, the SW Hellenic Arc and Trench system generates large shallow- and intermediate-depth earthquakes many of which have been reported since the early historic times. Magnitudes of up to 8.0 have been reported in the literature, (e.g. Papazachos, 1990; Papazachos and Papazachou, 1997). Although such figures may have been overestimated, (some of them were drawn on the basis of ancient and medieval archival data), they still signify the great seismogenetic potential of the area.

With such a setting and history, the area has attracted attention and in the recent past, a number of predictions of large events appeared in the literature. A large shallow earthquake of $M 7.7 \pm 0.5$ was forecasted by Wyss and Baer (1981) to take place, between 1980 and 1991, in a quiescent zone northwest of Crete and along the Hellenic Arc (rupture length $100 \pm 50 \mathrm{~km}$ ). A similar prediction was also made by Papazachos and Comninakis (1982), but a with a narrower time window. Such an event has yet to occur. The failure can partly be attributed to the fact that earthquake epicentres determined by the theretofore network of the Geodynamics Institute of the National Observatory of Athens and thought to lie south of the Aegean plate boundary in the African plate, were in fact located an average of $60 \mathrm{~km}$ to the NE (Papadopoulos et al., 1988). Such problems would, of course be detrimen- 


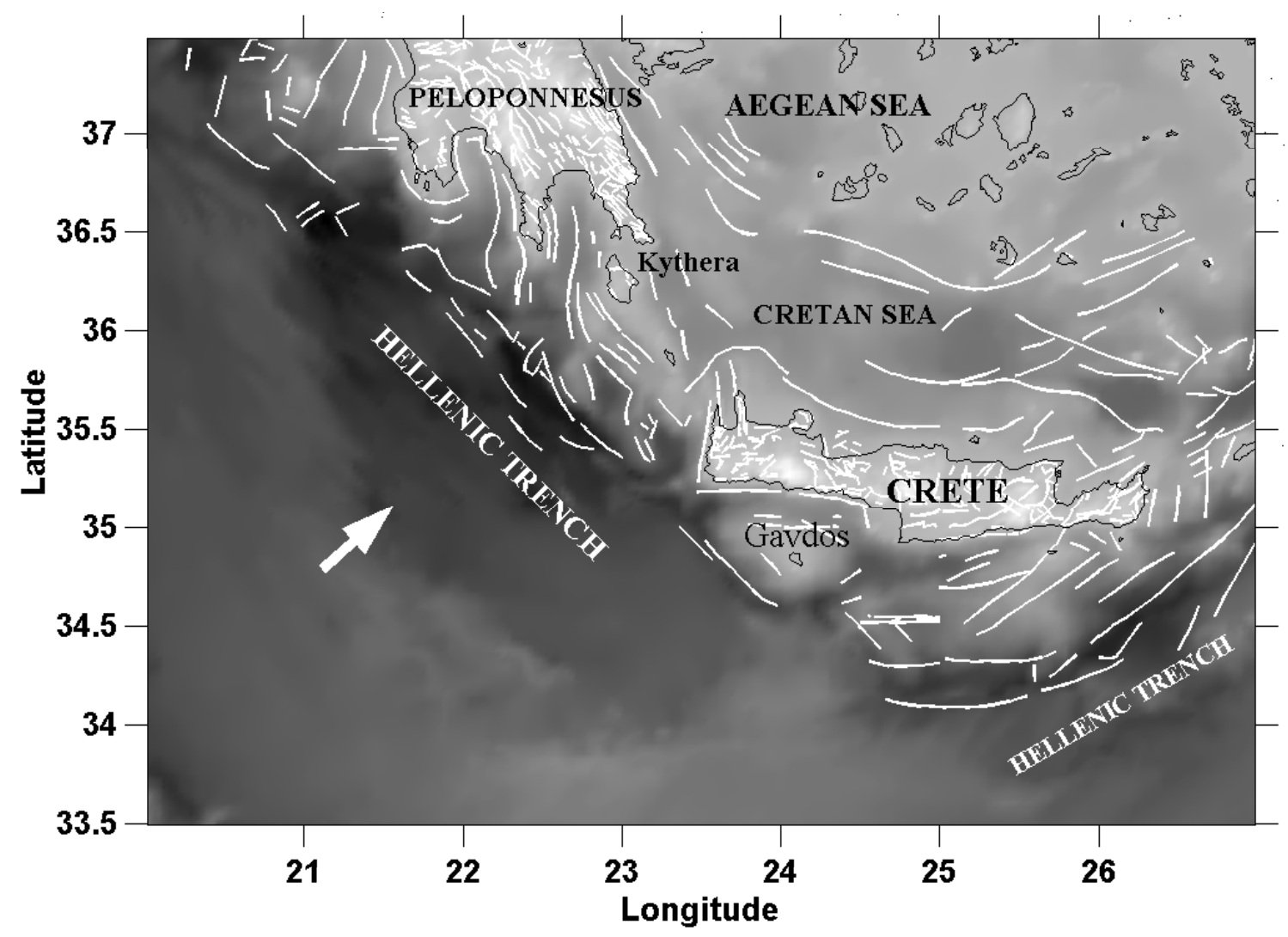

Fig. 1. The principal geotectonic and structural features of the SW Hellenic Arc and Trench system.

tal to any prediction made with methods requiring precise earthquake location data, as does the quiescence hypothesis. Ferraes (1985) reached a similar conclusion, but with the occurrence of the main event estimated for the decade 1992 to 2002. This period is also about to expire.

Sequences of accelerating seismic release rates have also been investigated and identified in the WSW Hellenic Arc. Prior to the appearance of the time-to-failure model, in a series of well constrained observational studies Papadopoulos (1986, 1988a, 1988b) identified a number of accelerating sequences comprising intermediate magnitude events $\left(M_{S} \geq 5.2\right)$ and has also claimed the successful prediction of the 13 September 1986 Kalamata earthquake. Retrospective analysis of intermediate magnitude seismicity was conducted by Papazachos and Papazachos (2000) and Papazachos and Papazachos (2001), on the basis of the accelerating time-tofailure model. These authors concluded that during 19481957, the four large, shallow main-shocks to have occurred in the area, (9 February $1948,35.5^{\circ} \mathrm{N}, 27.2^{\circ} \mathrm{E}, M=7.1$; 17 December $1952,34.4^{\circ} \mathrm{N}, 24.5^{\circ} \mathrm{E}, M=7.0 ; 9$ July 1956 , $36.6^{\circ} \mathrm{N}, 26.0^{\circ} \mathrm{E}, M=7.5 ; 25$ April $1957,36.5^{\circ} \mathrm{N}, 28.8^{\circ} \mathrm{E}$, $M=7.2$ ), were preceded by accelerating seismicity, typically in the range $M 4.5-6.8$. In a most recent publication, Papazachos et al. (2002) report of a similar accelerating seismicity pattern that has started several years ago and currently develops in the area. By modelling this sequence, they expect a magnitude $6.8 \pm 0.5$ event to take place up to year 2004.4.
Our interest in the area was motivated by our desire to test and evaluate the predictive capability of the $\mathrm{CP}$ model in a region that has been shown to generate accelerating precursory sequences, also given its history of large earthquakes and "failed" or "successful" predictions, and the absence of a strong earthquake in the entire southern Aegean area during the past few decades, which may indicate that such an event may be due. Unlike Papazachos et al. (2002), who focus on intermediate magnitude scale pre-shock activity, we include smaller events in the analysis (down to the magnitude of completeness), on the premise that $\mathrm{SOC}$ and $\mathrm{CP}$ processes are independent of scale and therefore, accelerating sequences should appear consistently at all magnitudes.

Independently of Papazachos et al. (2002), we have identified approximately the same areas of accelerating seismic release rates. In addition, we have also identified adjacent areas of decelerating seismic release rates. The configuration of the accelerating and decelerating sequences hint of a causal relationship between them, which we have tried to explain in terms of stress transferred by certain fault configurations preparing to rupture the area. Supposing that the $\mathrm{CP} /$ time-to-failure model does indeed describe the observed seismicity changes in the area, an obvious benefit of such an endeavour is our ability to better constrain and model hazard and risk from such an event by estimating the size, orientation and rake of the seismic source, as well as its average distance from inhabited or industrial areas. Our investigations 


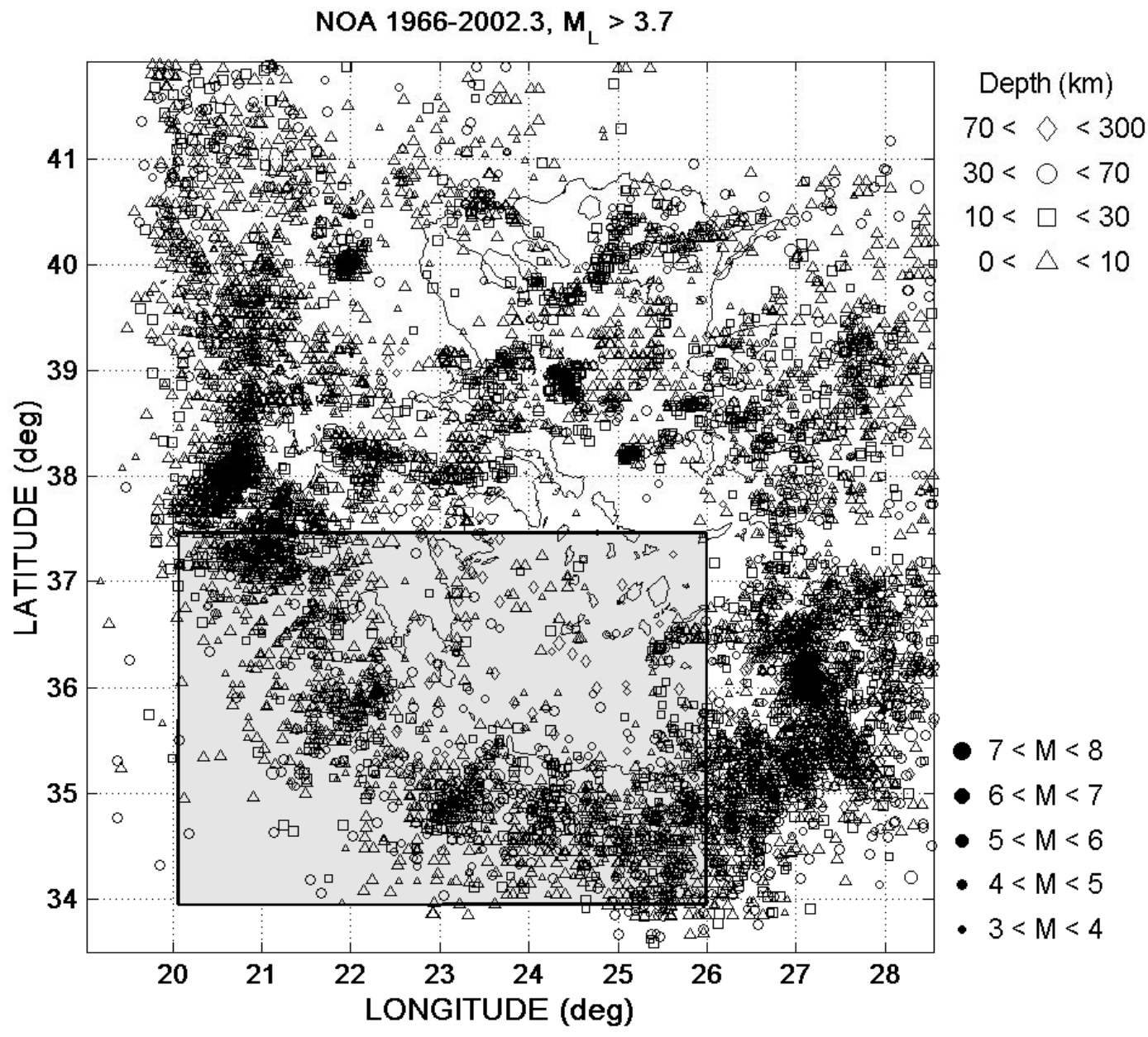

Fig. 2. The catalogue of the Geodynamics Institute of the National Observatory of Athens, spanning the period 1 January 1965 - 30 April 2002. The magnitude scale is $M_{L}$ (see text for details). The study area is defined by the grey shaded rectangle.

and results are reported in the following.

\section{Data conditioning and analysis procedures}

The seismicity data used in this study are taken from the raw catalogue of the Geodynamic Institute of the National Observatory of Athens (GI-NOA, http://www.gein.noa.gr/services/ cat.html) and span the period 1 January 1966 - 10 April 2002 (Fig. 2). This is the most detailed (but not most accurate) catalogue of Greek seismicity and contains upwards of 42000 events.

The GI-NOA reports local magnitudes $\left(M_{L}\right)$ and its catalogue is neither homogeneous nor complete. To investigate completeness, in Fig. 3a we present the frequency-magnitude statistics. Clearly, there are two magnitude bands with apparently different scaling, as is also obvious in the derivative $\mathrm{d}(\log \mathrm{N}) / \mathrm{d} M$ (triangles). The first is $M_{L} \approx 3-3.6$; the second is $M_{L} \approx 3.7-6.9$, with the upper end being the maximum observed during the studied period 1966-2002.3. We have insufficient information to decide whether this change is natural or artificial, due to differences in magnitude reporting between the larger and the smaller events. At any rate, for apparent reasons we conclude that a useful and reliable lower limit of completeness is $M_{S}=3.7$, i.e. the lower bound of the larger magnitude band.

To investigate (in)homogeneity, in Fig. $3 \mathrm{~b}$ we present the cumulative number curve for magnitudes $M_{L} \geq 3.6$ (solid line); this subset contains approximately 14800 events. Several time-local changes of seismicity rates exist, the two most prominent of which appear to coincide with periods of seismicity crises, (1980-1983 and 1995-1997), and can thus be attributed to the large number of aftershocks reported. There also appears to be a persistent rate change after year 1995. To decide what is what we declustered the catalogue using the method of Reasenberg (1985). This identifies in a series of earthquakes, which are correlated by means of Omori's law within a given radius and time window and replaces them with an equivalent event at the location of the leading largest earthquake, with magnitude corresponding to the total energy released during the sequence. In this way, the number of main events (hence background seismicity rates) remains intact. The cumulative number curve for the declustered catalogue is shown in Fig. 3b (dashed line). As antici- 

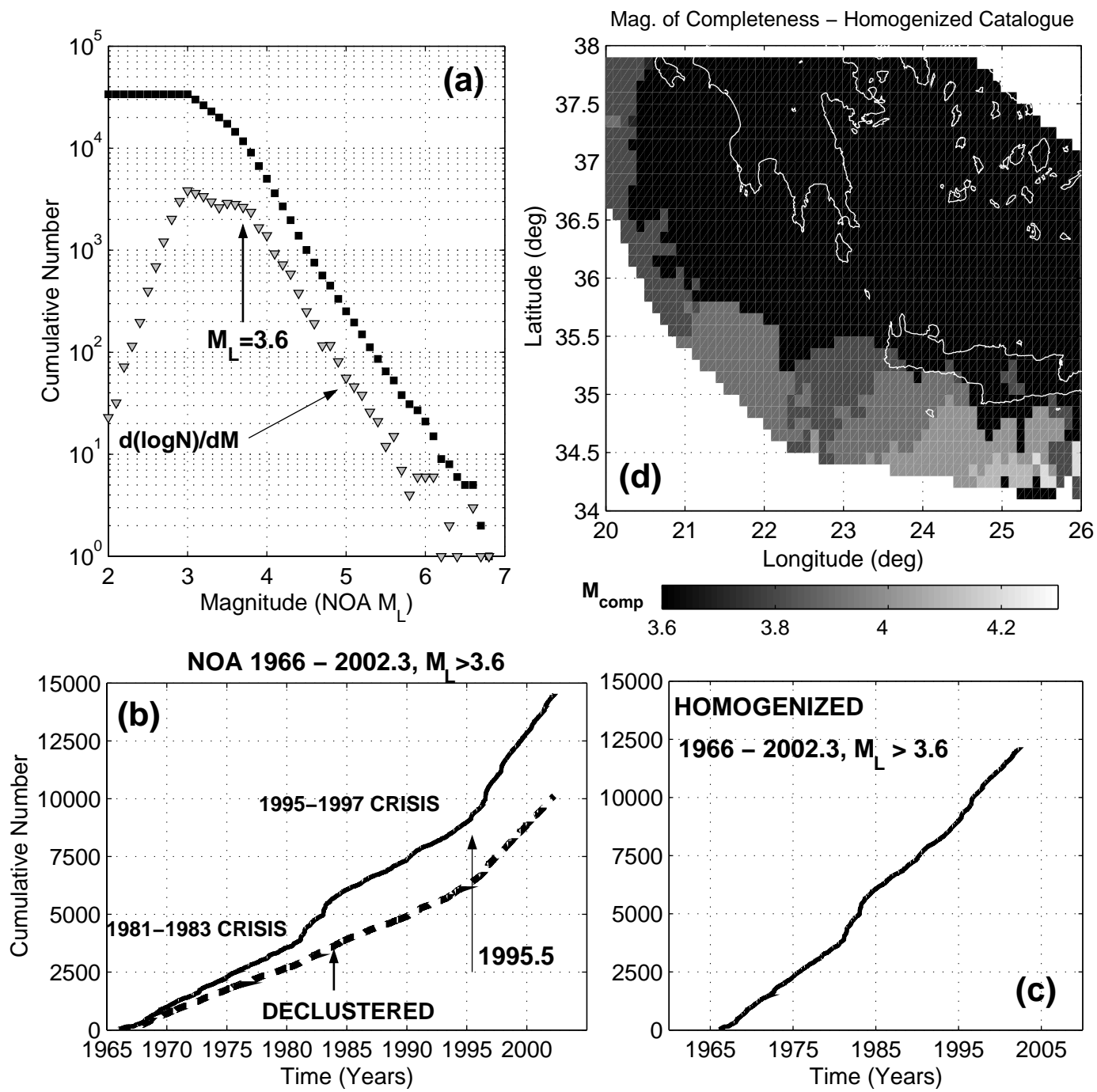

Fig. 3. (a) The frequency - magnitude statistics of the NOA catalogue. (b) The cumulative number curves of the raw NOA catalogue (solid line) and the declustered NOA catalogue (dashed line), above the magnitude of completeness $\left(M_{L} \geq 3.6\right)$. (c) The cumulative number curve of the homogenised NOA catalogue above the magnitude of completeness $\left(M_{L} \geq 3.6\right)$. ((d) Map of the magnitude of completeness, based on the homogenised NOA-ML catalogue. Grid dimension is $0.1^{\circ}$ square and calculations were based on a minimum of 200 events around each grid point.

pated, the time-local rate changes due to the seismicity crises have disappeared but the persistent rate change has been confirmed. It begins on year 1995.5 approximately, as identified with Habermann's GenAS procedure (Habermann, 1983). To quantify the rate change, we applied the method of Zúñiga and Wyss (1995) to compare the frequency-magnitude statistics and rates for two non-overlapping periods, $P 1=1970$ 1995.3 and $P 2=1995.4-2002.2$. We have thus determined that between the two periods the magnitudes are related as

$M_{P 2}=0.85 \cdot M_{P 1}+0.71$.

It appears that the post-1995 rate change can reasonably be attributed to a corresponding change in the procedure of magnitude reporting at NOA. Indeed, as of January 1995, NOA began upgrading its entire network from a purely analogue system based on leased line telemetry, first to a hybrid and then to a digital system based on leased data line telemetry. It is conceivable that small changes in magnitude calculations may have resulted from small changes in the recording and reading of the seismograms. Unfortunately, and since there has not been any performance analysis of the NOA network before and after the upgrade, there is no way of pinpointing the factors that effected the changes. Nevertheless, by using Eq. (4) it is possible to adjust the magnitudes of either period with respect to the other and thereby restore homogeneity to the catalogue. Herein, we have chosen to correct the magnitudes of $P 2$ with respect to $P 1$, which is considerably longer in duration. Figure $3 \mathrm{c}$ presents the cumulative number curve of the homogenised catalogue, which after the due adjustment for completeness contains nearly 12000 events with $M_{L} \geq 3.6$.

Even after homogenisation local and distributed variations 

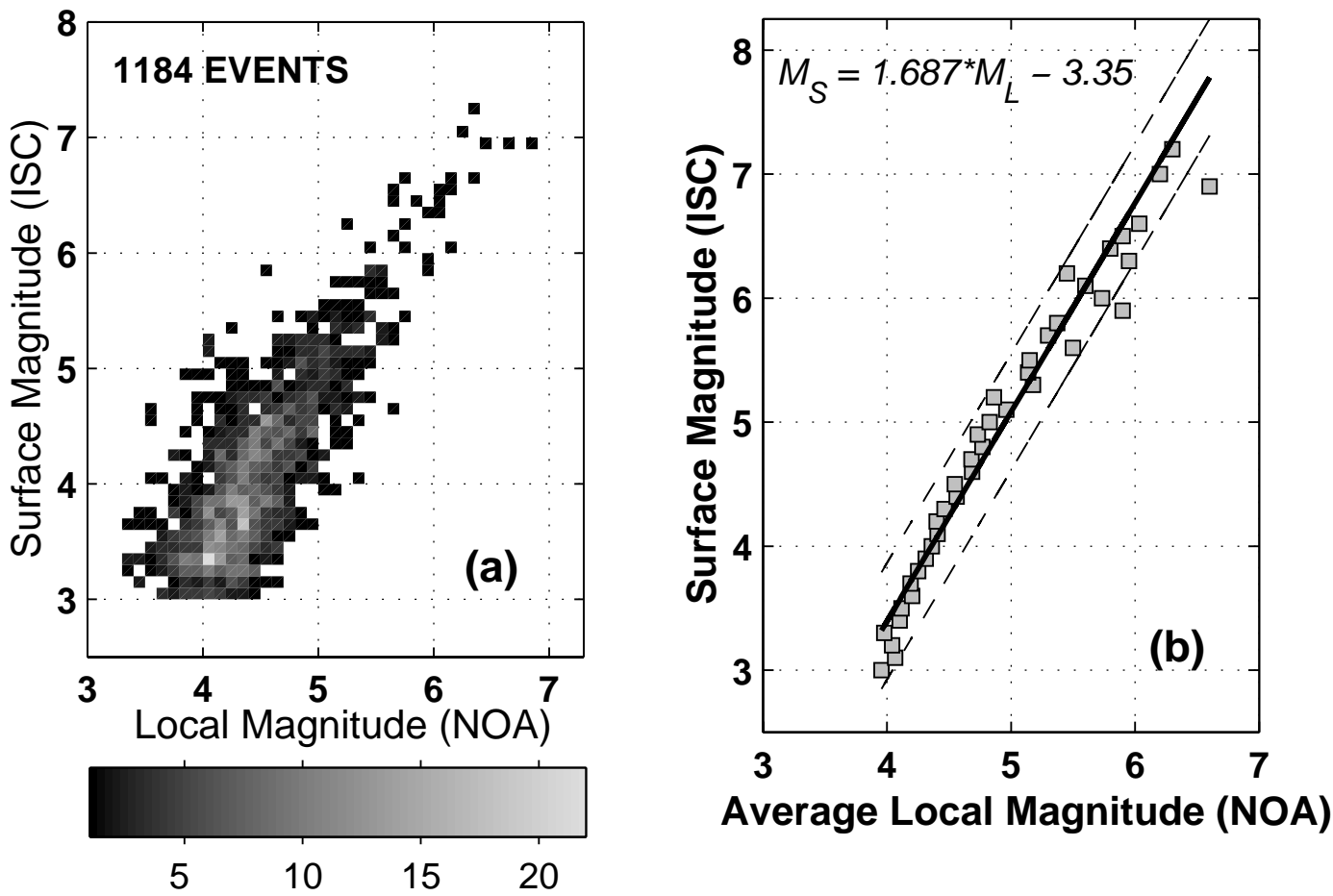

Fig. 4. (a) Graphical representation of NOA- $M_{L}$ vs. ISC- $M_{S}$ magnitudes for 1184 common events between 1 January 1978 and 30 April 2000. The shading represents the density of multiple mappings per magnitude interval. (b) The squares represent the row-wise NOA- $M_{L}$ weighted average magnitude vs. ISC- $M_{S}$, together with the best fitting straight line and $95 \%$ confidence limits.

in completeness may exist over an extended area. To check this problem in our study area, we compiled a magnitude of completeness map, calculated as per Fig. $3 a$, on a $0.1^{\circ}$ square grid, using a minimum of 200 events around each grid point. The result is shown in Fig. 3d. As evident, completeness deteriorates from $M_{L} \approx 3.6$ to $M_{L} \approx 3.9-4$ toward the periphery of the Hellenic Arc and Trench system. In consequence we consider that $M_{L}=3.9$ should rather be adopted as the absolute magnitude threshold for the ensuing analysis.

The energy $E_{i}(t)$ required by Eq. (3) can be estimated after Gutenberg and Richter (1956) as

$\log _{10} E_{i}(t)=4.8+1.5 \cdot M_{S}$,

which yields

$\log _{10} \varepsilon(t)=\log _{10} \sqrt{E_{i}(t)}=2.4+0.75 M_{S}$.

Kanamori and Anderson (1975) have shown that Eq. (5a) is consistent with what is expected theoretically for a classical crack model with a constant stress drop. The stress drop does not vary significantly with earthquake size (e.g. Kanamori and Anderson, 1975; Hanks 1977), at least down to seismic moments of the order $5 \cdot 10^{18} \mathrm{ergs},\left(M_{W} \sim 3\right.$ or $M_{S} \sim 1.5$, e.g. Hanks, 1977). Thus, Eqs. (5) comprise energy - magnitude scaling laws applicable over a broad range of magnitudes.

Since NOA reports local magnitudes, it is necessary to convert $M_{L}$ to $M_{S}$. To address this problem we have used the subset of the International Seismological Centre (ISC) catalogue that reports $M_{S}$ magnitudes, for the area of Greece and adjacent territories, as shown in Fig. 1 (ISC On-line Bulletin, http://www.isc.ac.uk/Bull). The NOA- $M_{L}$ and ISC- $M_{S}$ catalogues contain 1184 common events between 1/1/1978 and 30/4/2000. Figure 4a is a graphical representation of NOA- $M_{L}$ vs. ISC- $M_{S}$. If $j$ is a discrete variable spanning the $M_{L}$ magnitude range and $k$ is a corresponding variable over the $M_{S}$ magnitude range, then Fig. 4a shows a density matrix whose elements represent the number of $M_{L}$ magnitudes that map onto a given $M_{S}$ magnitude in the sense $N(k, j)=\left\{M_{L}(j)\right\} \rightarrow M_{S}(k)$, with \{.\} denoting an ensemble. The two magnitude scales are apparently linearly correlated for $M_{S}>3$ and $M_{L}>3.4-3.5$ and up to magnitudes of the order of 7. However, it is not recommended to compute a LS model of their relationship with the raw $M_{L}-M_{S}$ data set because there is considerable redundancy, i.e. multiple mappings of $M_{L}(j)$ onto $M_{S}(k)$, and heavy bias toward the lower magnitude ranges, thus producing a grossly unbalanced data set. To circumvent this problem, we chose to model the reduced data set $<M_{L}(k)>-M_{S}(k)$, where

$$
<M_{L}(k)>=\sum_{j} M_{L}(j)^{*} N(k, j) / \sum_{j} N(k, j)
$$

is the row-wise weighted average of the $M_{L}$ population and is shown in Fig. $4 b$ together with the $95 \%$ confidence limits. Using a robust re-weighted LS regression with a redescending bisquare influence function on the reduced data set, we obtained the best fitting line

$M_{S(I S C)}=M_{L(N O A)} \cdot 1.687 \pm 0.053-3.35 \pm 0.263$, 


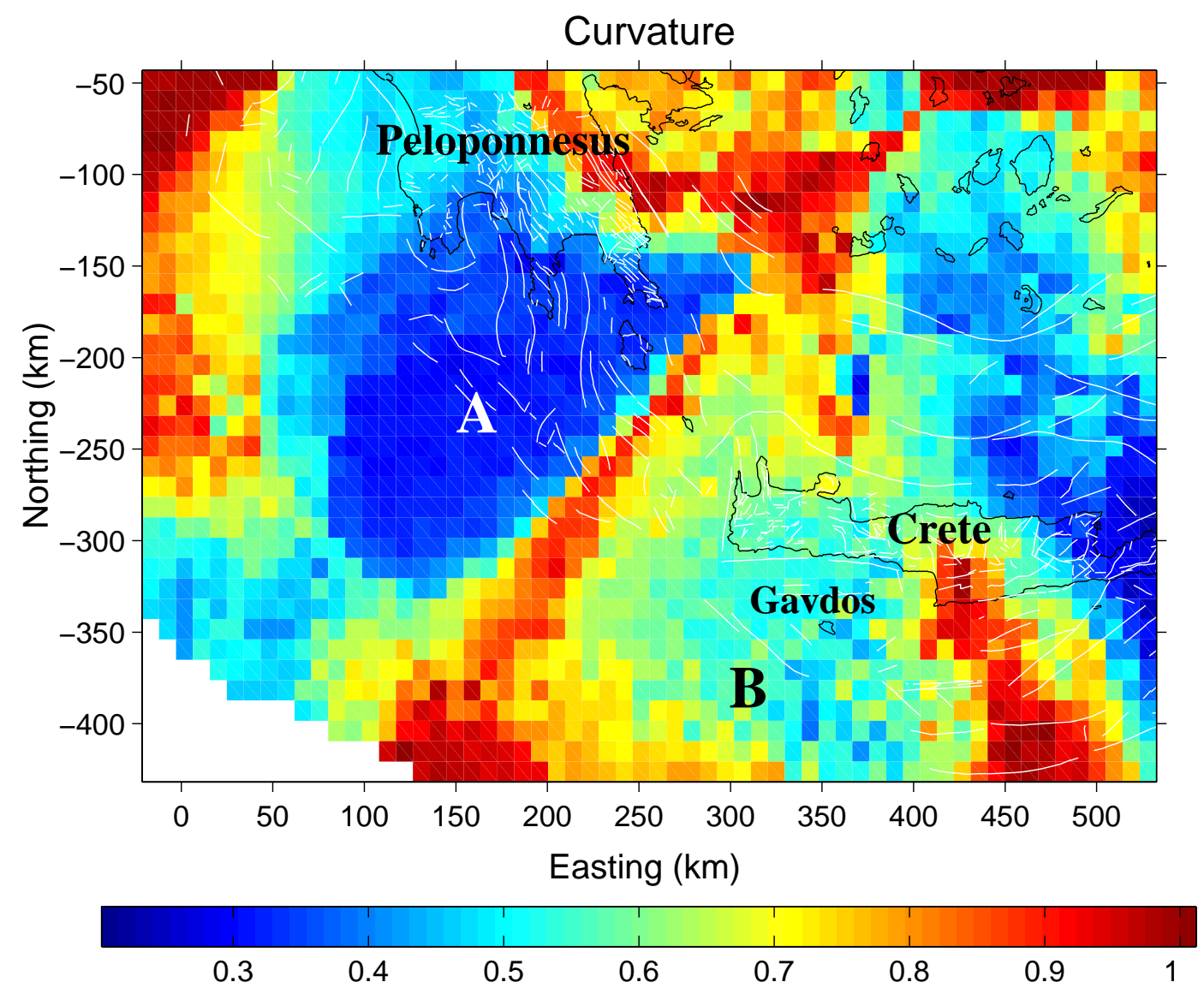

Fig. 5. Map of the curvature at the optimal radius, $C\left(R_{C}\right)$. Grid dimension is $0.1^{\circ}$.

which can be used to convert NOA- $M_{L}$ magnitudes to ISC$M_{S}$ and is also shown in Fig. 4b. Let us also point out that the $M_{L}$ magnitudes reported in the NOA catalogue appear to be biased downwards by about 0.5 in the range $3.5 \leq M_{L} \leq 6.5$, probably due to the low static magnification of the WoodAnderson instrument at NOA (e.g. see Margaris and Papazachos, 1999). This bias is compensated for in Eq. (6). Finally, we note that a linear relationship of the form (6) was also reported by Papazachos et al. (1997), but it was derived from a data set much smaller than the one we used herein.

The identification of power-law behaviour in seismic release rates is rather straightforward: the cumulative Benioff strain vs. time for earthquakes within a circle of radius $R$ is modelled with the time-to-failure power-law relation (3), using a Hedgehog non-linear optimisation procedure operating on the $L_{2}$ norm. At the critical time $t_{c}$, Eq. (3) reduces to $\varepsilon\left(t_{c}\right)=K$. Therefore, at any $t \rightarrow t_{c}$, Eq. (5b) can be used to obtain a predicted magnitude as

$\hat{M}_{S}=\left(\log _{10}[K-\varepsilon(t)]-2.4\right) / 0.75$.

Following Bowman et al. (1998), the performance of the power law fit against the null hypothesis of constant seismic release rate, is quantified by defining a curvature parameter $C=($ Power law fit RMS $) /($ Linear fit RMS $)$, such, that when the data are best described by a power-law curve, the RMS error will be small compared to the RMS error of the linear fit and $C$ will also be small. Such modelling of the cumulative Benioff strain is repeated over a set of expanding concentric circles. The radius $R_{c}$ such that $C\left(R_{c}\right)$ $=\min \{C(R)\}$ and the corresponding model parameters are deemed optimal and stored. The procedure is applied on a regular geographic grid and maps of the optimal curvature, critical exponent, critical time and predicted magnitude are compiled. In this way it is possible to identify regions of accelerating seismic release, which can be further investigated with more advanced techniques.

\section{Results}

Time-to-failure modelling is carried out on a $0.1^{\circ}$ square grid and the results are presented in Figs. 5 and 6. Figure 5 is a map of the curvature at the optimal radius, $C\left(R_{c}\right)$, where definite evidence of power-law evolution in seismic release rates can be observed. The lowest curvature values (of the order of 0.3) are observed at the Hellenic Arc and Trench, to the south of Peloponnesus (Area A). In addition, relatively low curvatures (0.4-0.6) are observed to the south of W. Crete, around Gavdos island, within the Hellenic Arc (Area B). A third area of low curvatures (of the order 0.3-0.4) observed 


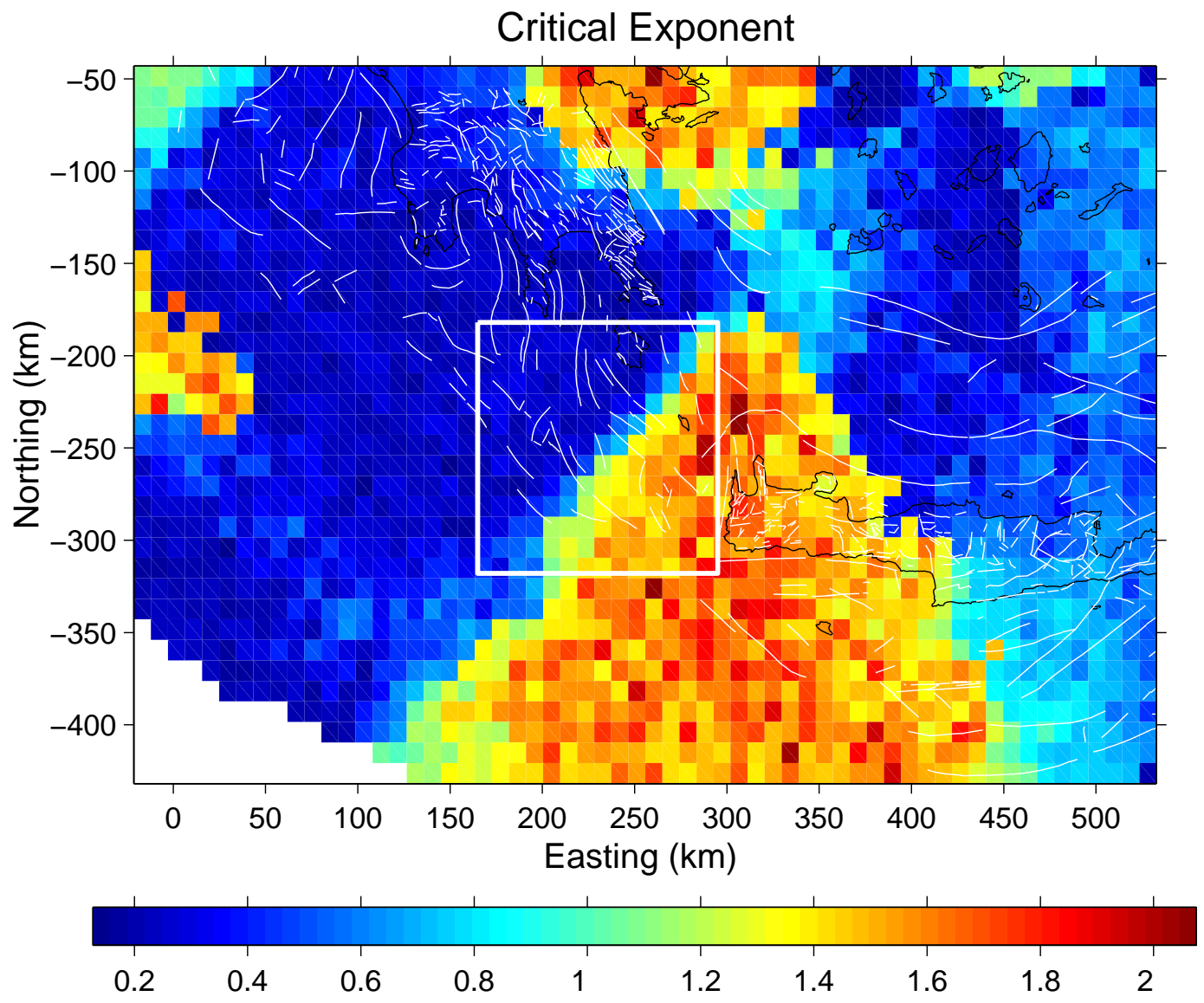

Fig. 6. Map of the critical exponent at the optimal radius, $n\left(R_{C}\right)$. Grid dimension is $0.1^{\circ}$.

around eastern Crete will be the subject of an independent study and will not concern us here. It should be noted, however, that unless otherwise constrained, good power-law models of seismic release rates can be obtained either when they are accelerating (the critical exponent $n<1$ ) or decelerating $(n>1)$. By inspecting the corresponding map of the optimal critical exponent $n\left(R_{c}\right)-$ which is shown in Fig. 6, it is possible to distinguish between accelerating and decelerating sequences. The distribution of the critical exponent shows a well structured four-leaf pattern, in which quadrants with exponents greater than unity and quadrants with exponents smaller than unity alternate, separated with almost sharp boundaries. Closer inspection reveals that the Area A of low curvatures is associated with critical exponents $n\left(R_{c}\right)$ of the order of $0.2-0.35$, consistent with expectation for $\mathrm{CP}$ behaviour. Conversely, the Area B is associated with critical exponents $n\left(R_{c}\right)$ of the order of 1.4-1.8 and relatively strong deceleration. Note however that in the context of the CP model, Eqs. (1) and (3) have definite physical meaning only for accelerating sequences; they have uncertain physics and no predictive value in the case of decreasing seismic release rates. In consequence, the estimated critical times and predicted magnitudes are significant only in the neighbourhood of Area A. In order to have some idea about the stability of the modelling procedure, we compute the means and stan- dard deviations of predicted magnitudes and critical times of models computed at the grid nodes of Area A, subject to the constraints $C\left(R_{c}\right) \leq 0.4$ and $0.15 \leq n\left(R_{c}\right) \leq 0.35$. The resulting populations contain upwards of 200 realisations of the relevant parameters, from which $\left.<\hat{t}_{c}\right\rangle=2003.6 \pm 0.55$ and $<\hat{M}_{S}>=7.1 \pm 0.4$.

The results are quite stable and consistent. Nevertheless, the picture may not be as bright - if we attempt to derive the same parameters from a different starting point. Specifically, another method of predicting the magnitude involves the size of the scaling region around the culminating event. On the basis of CP theory, Bowman et al. (1998) conclude that $\log R \propto 0.5 M$ and also provide an empirical linear relationship in which $\log R \propto 0.44 M$. Papazachos and Papazachos (2000) provide for the Aegean area, the relationship $\log R=0.41 M-0.64$, where $M$ is the moment magnitude. The mean optimal radius $\left(R_{c}\right)$ at Area $\mathrm{A}$ is $102 \pm 14.4 \mathrm{~km}$ (grid nodes with $C\left(R_{c}\right) \leq 0.4$ ). Using either relationship above, and with due adjustment of the moment to surface magnitudes, we find $\hat{M}_{S}=6.3-6.6$. Thus we run into an apparent contradiction that should not be: Predicted magnitudes computed by direct modelling are significantly higher than predicted magnitudes computed indirectly, from empirical relationships based on observational studies. We also note that the problem persists, no matter how one doctors 
Fault relaxed, Regional Stress relaxed

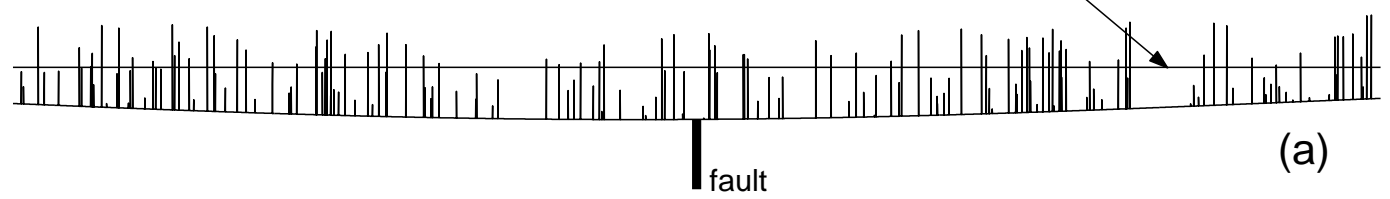

Fault stresses up / regional field stresses up

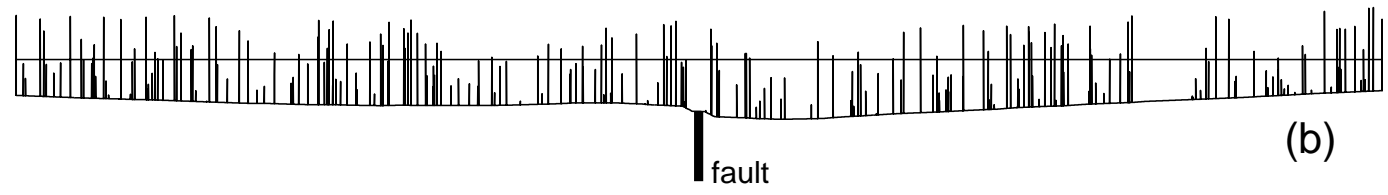

Stress-up continues ...

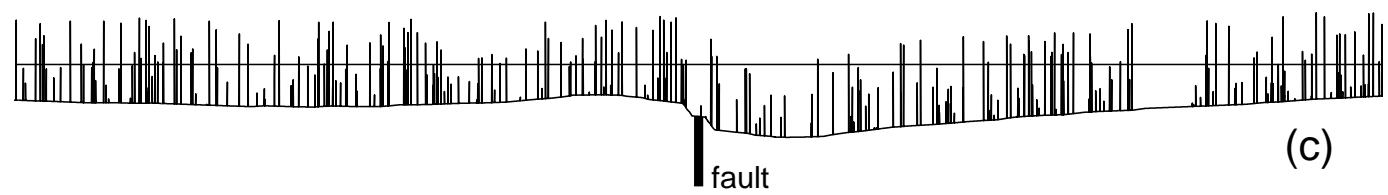

Stress-up nearing point of failure

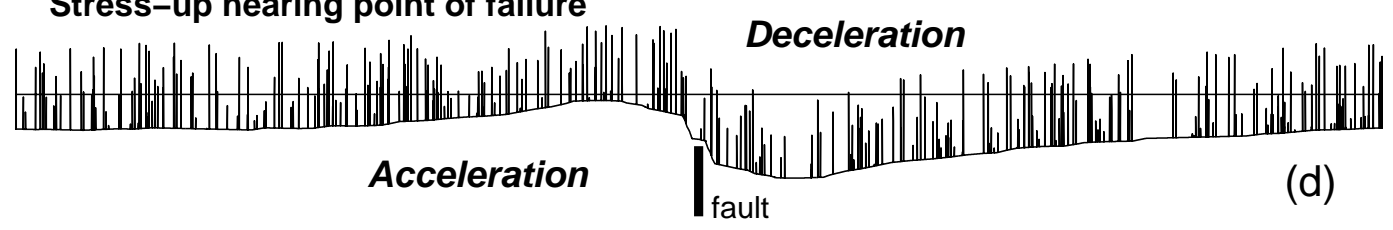

Fig. 7. Schematic representation of a physical model, whereby the observed characteristics of accelerating seismic release rates can be understood in terms of simple elastic rebound and stress transfer from a fault, to a region already subjected to stress inhomogeneities. (a) At the beginning of the cycle, the regional stress is relaxed and local inhomogeneities produce local instabilities. (b-d) With time, at some areas positive stress transfer and build up causes progressively more local failures (acceleration). Conversely, at areas of negative stress transfer, progressively fewer local failures are expected (deceleration).

with the size of the optimal radius or the apparent size of Area A.

$\mathrm{CP}$ theory does not make any particular predictions about the configuration or shape of the critical region around the approaching large earthquake. In fact, it was initially thought that the critical region extends everywhere around the future epicentre and hence the earlier methods of searching for acceleration in circular domains (e.g. Varnes, 1989; Bufe and Varnes, 1993; Bufe et al., 1994; Sornette and Sammis, 1995; Brehm and Braile, 1998, 1999; Bowman et al., 1998, and others). If this was the only physical possibility, then the contradiction would be bad news as it would point toward inconsistencies, either in the theory, or in the observational studies, or in both.

The physical models of accelerating seismic release may provide an explanation and particularly so, the idea of Bowman and King (2001) that the observed characteristics of distributed accelerating seismicity may be produced by increasing tectonic stress in a region already subjected to stress inhomogeneities. Unlike methods using circular or elliptical regions to search for accelerating seismicity, this approach defines the critical region in terms of the stress field required to rupture a fault with a specified orientation and rake. This model can possibly explain observations of decelerating seismicity as well, because during earthquake preparation cycle, stress does not evolve uniformly around the fault. Rather, there exist "bright spots" where stress is increasing by transfer from the fault, and shadows where stress may even be relaxing. The configuration of these volumes depends of the nature and geometry of the fault and whereas acceleration may be observed in stress bright spots, deceleration may be expected in stress shadows. This concept is schematically illustrated in Fig. 7. At the beginning of the cycle, the regional stress is relaxed due to the stress shadow of a previous large earthquake and local stress inhomogeneities may rupture local faults when their level exceeds some failure threshold (Fig. 7a). With time, the regional stress increases at some areas, where progressively more local stress inhomogeneities are likely to exceed the failure threshold and rupture, producing acceleration of seismic release rates (Figs. $7 b-d$ ). Conversely, at areas of stress decrease, progressively fewer local inhomogeneities are likely to rupture; this amounts to an ap- 


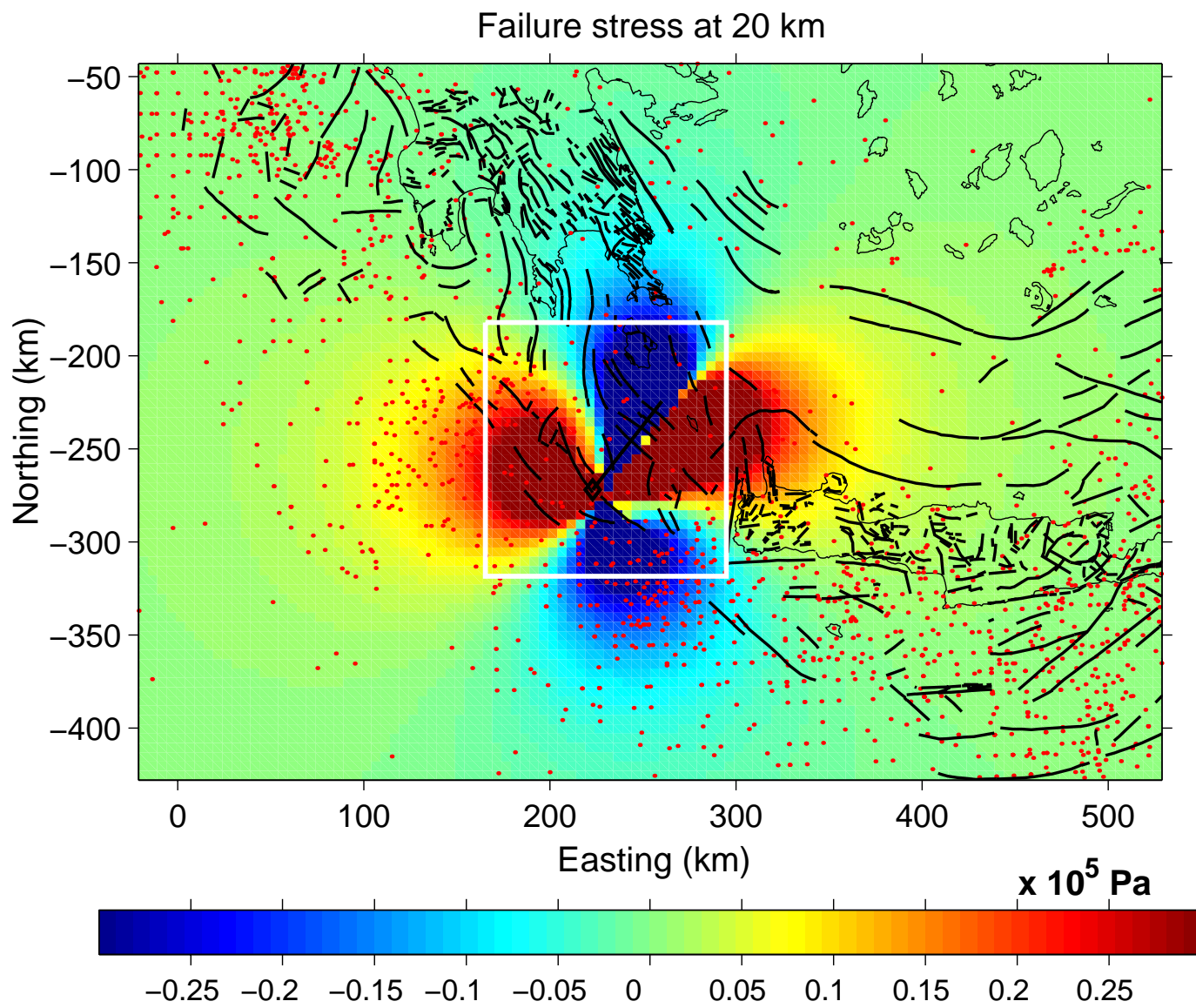

Fig. 8a. Failure stress due to a NE-SW oriented strike - to oblique-slip fault (thick black line, $\varphi=35^{\circ}, \delta=80^{\circ}, \lambda=-35^{\circ}$ ), capable of producing an $M_{S}=7.1$ earthquake in a homogeneous medium with Young's modulus $7 \cdot 10^{7} \mathrm{~Pa}$. Failure stress is defined as $\left(\sigma_{1}+\sigma_{3}\right) / 2$ and the calculation is taken to the depth of $20 \mathrm{~km}$. The white rectangle encloses the area where a family of similar faults produces a similar stress distribution, which may explain the observations of accelerating seismic release rates. The colour-code of stress variations represents the interval $-3 \cdot 10^{4} \mathrm{~Pa}$ to $+3 \cdot 10^{4} \mathrm{~Pa}$. Red dots are earthquake epicentres.

parent decrease of seismic release rates. At this point we note that hitherto observational studies have focused on acceleration, since this is the main prediction of the CP model. In general, non-linear deceleration has not been researched as a possible precursory effect, let alone that even the precursory quiescence hypothesis does not predict such a phenomenon. Herein we observe both effects in such a well structured and organised manner, which is strongly suggestive of a causal relationship.

To investigate whether the above hypothesis may explain our observations, we define a fault with a given size, orientation and rake and back-slip it in order to determine the areas of stress increase/decrease prior to the earthquake, using the 3-D boundary element fault modelling program 3D-DEF by Gomberg and Ellis (1994). The Earth's crust is necessarily assumed to be homogeneous and the geometry of the fault plane is kept simple, inasmuch as there is practically no information on the characteristics of real fault planes capable of rupturing at the study area.

After several trials, we concluded that both accelerated and decelerated seismic release patterns can possibly be ex- plained with a family of NE-SW, left-lateral, strike-slip to oblique-slip faults, capable of producing earthquakes with magnitudes $M_{S} \sim 7$. These faults are located within the rectangle shown in Figs. 6 and 8a. A representative member of this family produces the failure stress distribution of Fig. 8a, where failure stress is defined as $\left(\sigma_{1}+\sigma_{3}\right) / 2$. It has orientation $\varphi=35^{\circ}$, dip $\delta=80^{\circ}$, rake $\lambda=-35^{\circ}$, depth of burial $5 \mathrm{~km}$ and is capable of producing an $M_{S}=7.1$ earthquake in a homogeneous medium with Young's modulus $7 \cdot 10^{10} \mathrm{~Pa}$. As evident, stress increase is observed in area A where acceleration is also observed and stress decrease in area B where deceleration is observed.

We emphasize that no other significantly different fault geometry can account for all of the observations! However, we also note that the depth to the fault cannot be adequately constrained. Whether it is outcropping at sea-bottom or is buried at a depth of, say, $50 \mathrm{~km}$, the fault will produce very similar patterns of stress bright spots and shadows. To illustrate this point, in Fig. $8 \mathrm{~b}$ we present the $1 \mathrm{kPa}$ iso-surfaces of stress bright spots for two faults. The first is a shallow fault, exactly as per Fig. 8a. The second has exactly the same geometry, 


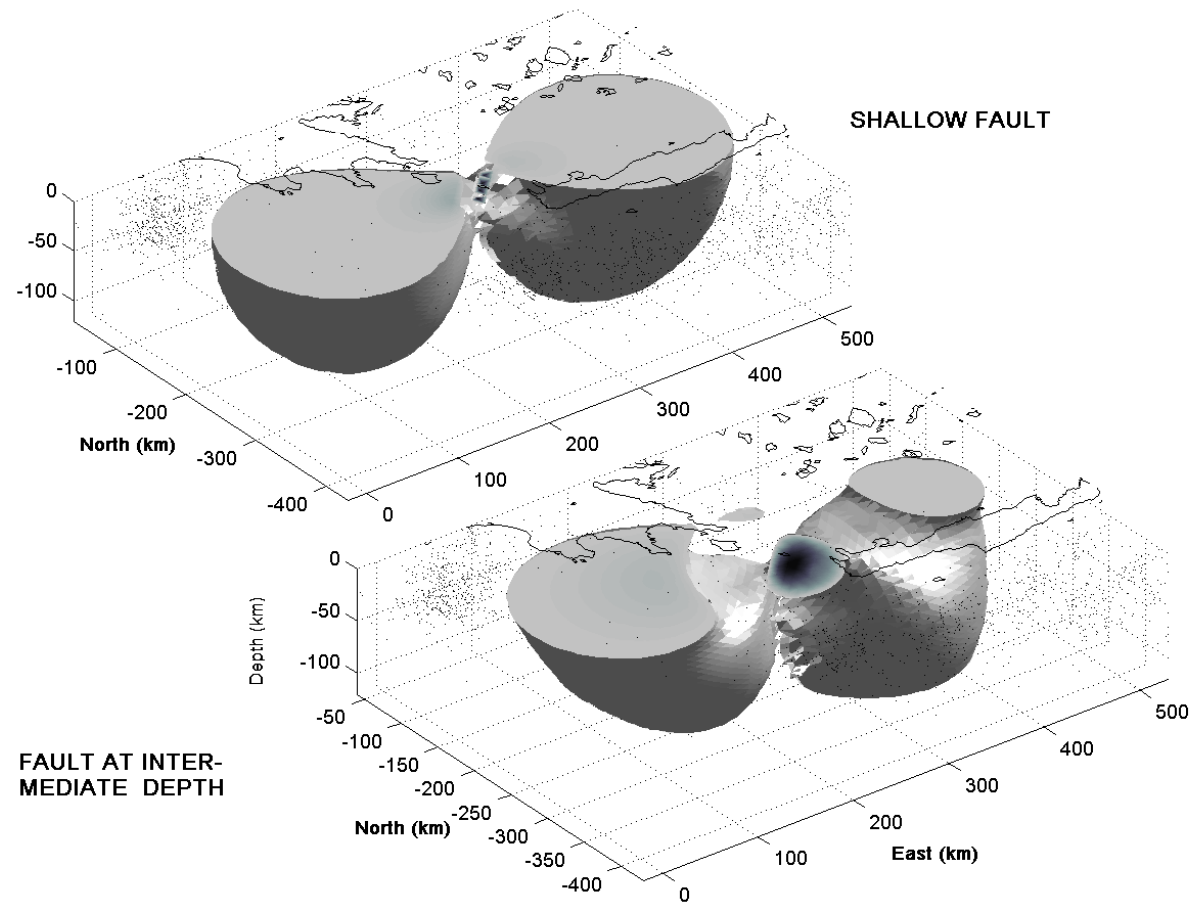

Fig. 8b. The upper left panel shows the $1 \mathrm{kPa}$ iso-surface (positive stress lobes) due to a shallow fault with characteristics $\varphi=35^{\circ}, \delta=80^{\circ}$, $\lambda=-35^{\circ}$, capable of producing an earthquake of magnitude $M_{S}=7.1$. The lower right panel shows the $1 \mathrm{kPa}$ iso-surface due to an intermediate depth fault (buried at $50 \mathrm{~km}$ ), with identical geometry. The crustal volumes within the surface experience stress increase greater than $1 \mathrm{kPa}$. Earthquakes hypocentres have also been superimposed (black dots).

but is buried at the intermediate depth of $50 \mathrm{~km}$. Earthquake hypocentres have also been superimposed (black dots). As can be seen, in both cases the volume of stress increase (inside of the iso-surfaces) includes all earthquakes of area A, with differences concerning only a handful of events. Similarly the volume of stress decrease includes all earthquakes of area B, again with very minor differences. Without additional data, it is rather difficult to infer about the depth of the fault at this point in time.

Another important question is of whether it is possible to have this kind of strike-slip fault in the SW Hellenic Arc, which comprises the accretionary prism of a subduction zone. Hitherto work on fault plane solutions of 20th century earthquakes has not observed evidence of strike-slip faulting at shallow crustal depths. There is, however, evidence of NE-SW strike-slip faulting at intermediate depths (a classification of known focal mechanism in the Aegean area can be found in Papazachos and Papazachou, 1997). However, it has to be noted that reliable focal mechanism data exist for the last third of the 20th century only. It is more than certain that within this very short period, not one large fault has ruptured. Likewise, not all faults capable of producing intermediate-size earthquakes with all possible permissible mechanisms have ruptured. The available data sample is simply not large enough to allow definite conclusions and comprises (at best) a large sample of the existing possibilities. Thus, while an intermediate depth NE-SW strike-slip rupture with the detected characteristics is altogether possible, a rel- atively shallow fault cannot be ruled out, as it may comprise a transcurrent structure facilitating the SW-ward motion of the Aegean plate and the tectonic setting of the area does not preclude it.

Returning to our analysis and in order to provide some numbers and a measure of the acceleration rates in the areas of stress increase, Figs. 9a-d illustrate models of the accelerating seismic release at Area A, at the west positive lobe of the stress field of Fig. 8a, computed with earthquakes laying inside the $5 \mathrm{kPa}$ contour (Fig. 9a), $2.5 \mathrm{kPa}$ contour (Fig. 9b), $1 \mathrm{kPa}$ contour (Fig. 9c) and $500 \mathrm{~Pa}$ contour (Fig. 9d). It is evident that while the sampled area increases from 16000 to over $82000 \mathrm{~km}^{2}$, and the number of earthquakes modelled increases from 190 to 225,283 and 310, respectively, the predicted parameters remain remarkably stable: $\hat{M}_{S}$ is 7.2 , 7.1, 7.2 and 7.3, respectively, and $\hat{t}_{c}$ is 2003.744, 2003.464, 2003.427 and 2003.484, respectively, all in agreement with the results obtained above. At the same time, the critical exponent remains at the level of 0.25 throughout, as predicted by the spinodal instability model of Rundle et al. (2000), indicating that at this point in time, this particular fault network acts like a CP system at the verge of a first order phase transition. The remarkable consistency of the results of Figs. 9a-d can possibly be due to the fact that all earthquakes used for modelling may still lay inside the correlation length of the stress-stress interactions stimulated by the fault. In other words, the boundary of the critical scaling region is still beyond the $500 \mathrm{~Pa}$ contour. Indeed, the radius of a cir- 

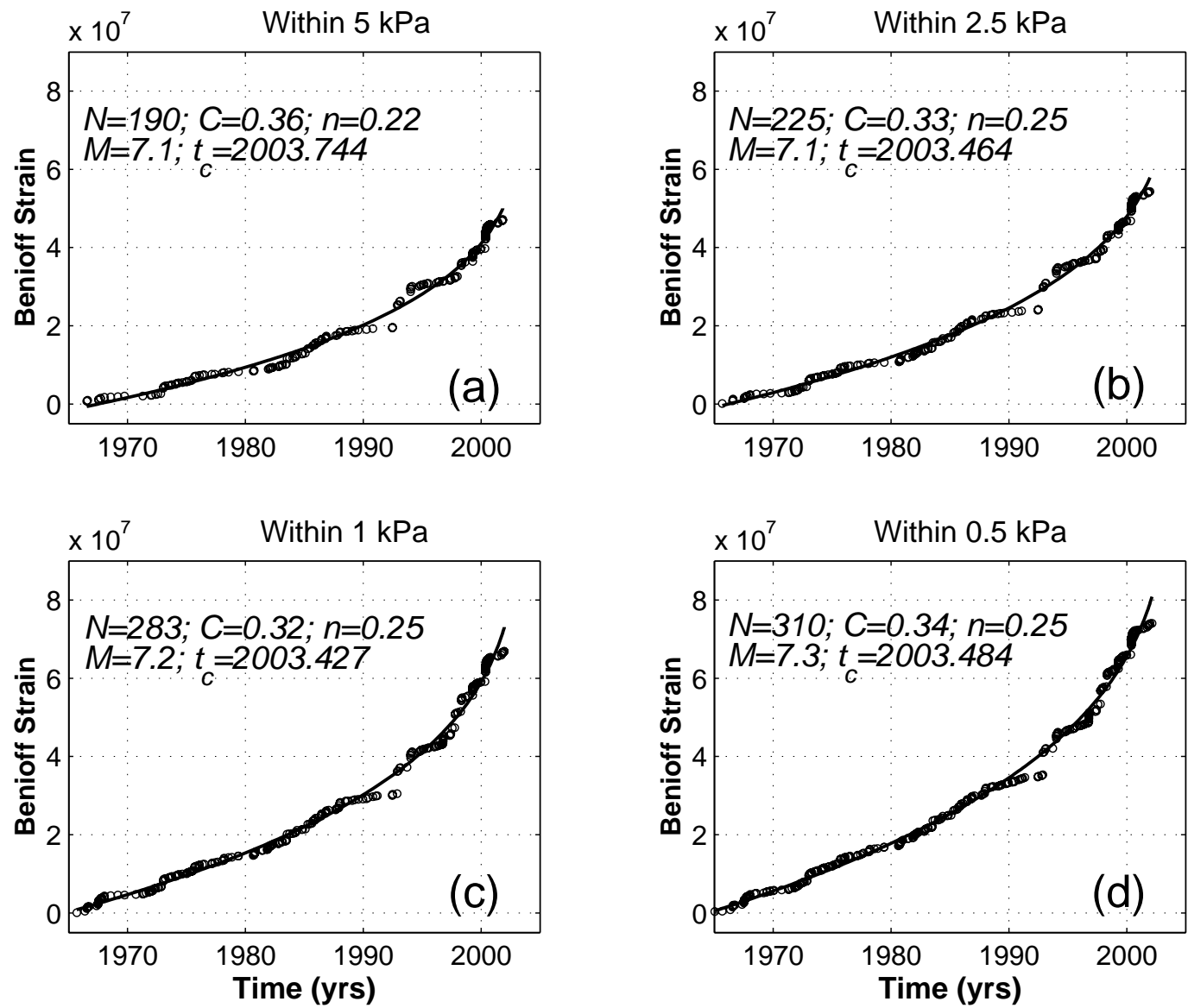

Fig. 9. Models of accelerating seismic release at Area A, in the western positive lobe of the stress field, computed with earthquakes (a) within the $5 \mathrm{KPa}$ contour, (b) within the $2.5 \mathrm{KPa}$ contour, (c) within the $1 \mathrm{KPa}$ contour, (d) within the $500 \mathrm{~Pa}$ contour. In each graph the cumulative Benioff strain is shown with small open circles. The continuous line indicates the best fitting power-law model.

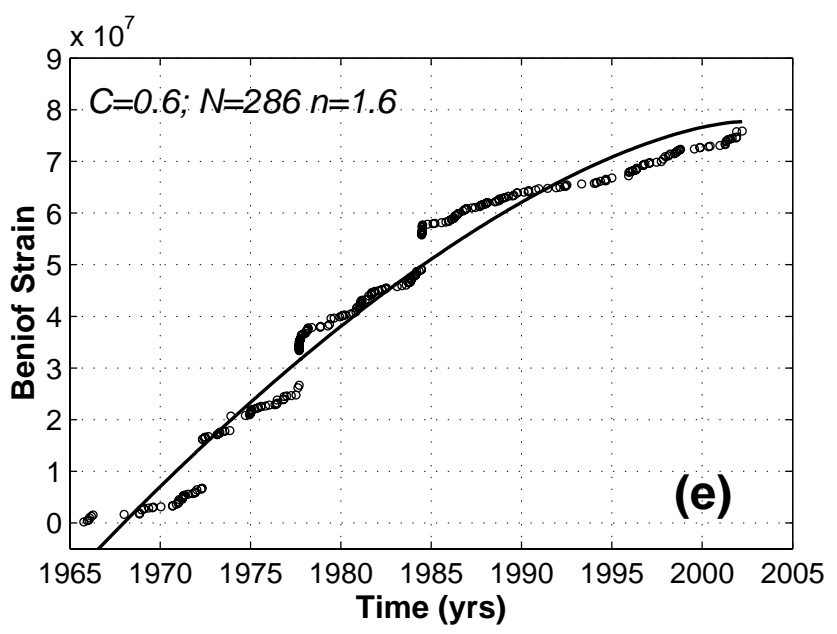

Fig. 9e. A model of decelerating seismic release at Area B, in the eastern negative lobe of the stress field, computed with earthquakes inside of the $-5 \mathrm{KPa}$ contour.

cle with area equivalent to the area of the $500 \mathrm{~Pa}$ contour is approximately $162 \mathrm{~km}$. Upon using the radius - magnitude scaling relationships quoted above, we find that the culminating event will have magnitude $\hat{M}_{S}=6.95-7.1$, slightly smaller, but in excellent agreement with the results of modelling. Quite reasonably, if the above explanation of our observations corresponds to true Earth processes, it will be very difficult to determine the exact extent of the scaling region, because at some point, it will interact with the scaling regions of other major faults. Finally, Fig. 9e shows a model of the decelerating sequence in Area B, constructed with earthquakes inside of the $-5 \mathrm{KPa}$ contour. This is shown only for the sake of completeness, since Eq. (3) has no predictive value for decelerating sequences.

In the light of the above evidence, it is possible to explain why it was not possible to calculate consistent magnitudes from the size of the circular optimal radii in Area A. The relatively small size of the optimal radii (and of Area A thereof), can be explained as result of data statistics. For so long as the search radius remained inside the true scaling region defined by the non-circular area of increasing stress, the time-to-failure model would return consistent estimates of the critical time and predicted magnitude. However, once 

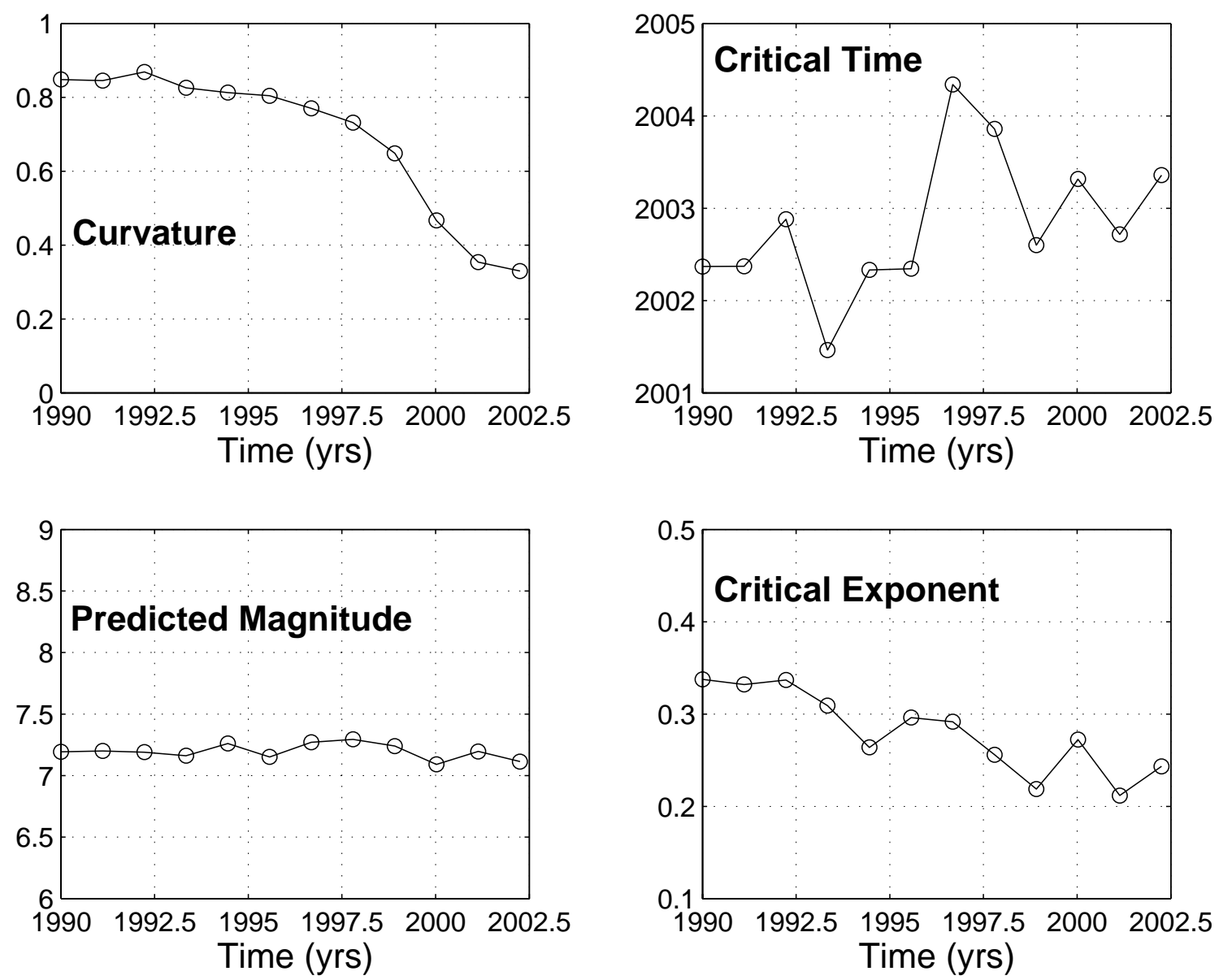

Fig. 10. Unconditional running forecast of an accelerating sequence. Computations are carried out at 12 cut-off times between 1990 and 2002, using the earthquakes located in Area A, inside of the contour $C\left(R_{C}\right)<0.4$ of Fig. 5 .

the search radius grew so large, as to surpass the boundaries of the scaling region, the contribution of uncorrelated earthquakes would quickly destroy the power-law behaviour of the cumulative Benioff strain: the true size of the scaling region and any associated parameters would be misestimated.

Albeit remarkable, these results should be viewed with due caution. The fault model is a simple plane rupturing a homogeneous continuum and cannot be expected to account for all the details of the observations; these result from the interplay between the material properties and stress distribution in the real crust (which are unknown and cannot be modelled with precision), and the statistics and constitution of the earthquake sample processed at each grid point. Moreover, the geometry of the NOA network at the SW Hellenic Arc is such, that systematic, sometimes considerable location errors may be expected (e.g. Papadopoulos et al., 1988). The situation has improved in the past decade but the problem is still not solved. While this is certainly a significant disadvantage, it does not have a detrimental effect on determining the approximate extent of the scaling region, as this comprises a rather large crustal volume over which the observations are integrated. It may, however, complicate the modelling of faults capable of producing these changes.

\section{Discussion and conclusions}

We have detected and investigated power-law acceleration of seismic release rates in the SW Hellenic Arc, consistent with the Critical Point earthquake model. Our observations are consistent with physical models of the seismic cycle, which predict such an effect as the result of regional stress increase and the establishment of long-range stress-stress correlations over the fault network involved in the preparation of a large event (Heimpel, 1997; Ben-Zion and Lyakhovsky, 2001; Bowman and King, 2001; King and Bowman, 2001). Moreover, our observations are consistent with the view of the power-law acceleration of seismic release as a particular type of self-organising $\mathrm{CP}$ systems undergoing a repetitive series of first order phase transitions (spinodal instabilities), as discussed in Rundle et al. (2000).

The model of King and Bowman (2001) on one hand and the theory of Rundle et al. (2000) on the other, while very different in approach and formulation, share a very important and defining characteristic. King and Bowman (2001) base their model on the decay of a stress shadow which is perturbed by fractal noise representing local stress inhomogeneities. The number and size of model events increases 
due to the corresponding increase in the number and size of stress patches above a failure threshold and this can be interpreted as an effective increase of the correlation length. Spinodal phase transitions are possible in systems with longrange interactions, which act to stabilise them against small fluctuations. Accordingly, Rundle et al. (2000), show that the stress-stress correlation length increases proportionally to the inverse square root of the time-to-failure. This of course, amounts to dynamic self-organisation of the fault network. Thus, in both cases the acceleration of seismic release is a consequence of increasing the span of interactions through the activated fault network.

As indicated by Huang et al. (1998), the critical nature of large events results from the interplay between the longrange stress-stress correlations of the self-organised critical state and the hierarchical fault structure in such a way, that hierarchical rupture at a given level is like a critical point to the lower levels. Thus, triggering of distributed failures in the area of stress increase may cause stress redistribution that triggers more faults at neighbouring regions, and so on. Such interactions between small events smooth the stress field and establish long-range stress correlations over the critical area, producing with time hierarchical ruptures: the many-fault interactions may account for the power-law behaviour of the accelerating seismic release with a critical exponent equal to 0.25 . We shall refrain from pursuing this discussion any farther, inasmuch as we intend to present a thorough theoretical development of the topic in a follow-up work.

It appears that our analysis has produced all the elements required for earthquake prediction, albeit of medium-term: Location, (SW Hellenic Arc, between Crete and the Peloponnesus), time (2003.6 \pm 0.6$)$ and size of the event (7.1 \pm 0.4$)$. In addition, if the physical model upon which we have based the interpretation is correct, we may have even determined the main characteristics of the fault that is going to rupture $\left(\varphi \approx 35^{\circ}, \delta \approx 80^{\circ}, \lambda \approx-35^{\circ}\right.$ ), albeit not its burial depth. For the given geotectonic setting, data and analysis procedures, the predicted parameters appear to be fairly reasonable. However, are they? Is this really a prediction?

It is difficult to give a clear cut answer. Time-to-failure modelling of accelerated seismicity is a relatively new field of study with few cases-histories from which to draw experience, most of which in fact comprise retrospective analyses of past earthquakes. Still, very little is known as to the development of real-time situations and their probability of success or failure. Also note that the scaling law (3) is essentially the result of a renormalisation process. Its underpinning is the concept of a scaling region in the time and space before a large rupture, assuming that the process of failure at a small spatial scale and temporarily far from a global event can be remapped (renormalized) to the process of failure at a larger scale and closer to the global event. By this re-mapping, the area of the pre-seismic release scales with the magnitude of the earthquake, which is like saying that the total energy released prior to global failure scales with the energy to be released at global failure. Its usefulness " ... is based on the existence of a scale invariance or self-similarity of the underlying physics at the critical point, which allows one to define a mapping between physical scale and distance from the critical point" (Sornette and Sammis (1995). In consequence, when a new element is added, (i.e. a large pre-schock), the sequence is renormalized and the predicted parameters may change, sometimes significantly.

To reassert this point, in Fig. 10 we illustrate the unconditional running forecast of an accelerating sequence, carried out at 12 cut-off times between 1990 and 2002.2, using the earthquakes located in Area A, within the contour $C\left(R_{c}\right)<0.4$ (Fig. 5). The evolution of the acceleration, from barely significant to fully developed power-law behaviour is evident in the reduction of curvature from 0.8 to 0.4 . The critical exponent remains at the level $0.2-0.3$ and the predicted magnitude is very stable. However, the estimated critical time changes from year 2000.2 to year 2004, although it is apparently trying to stabilize during the latter times of the sequence. Thus, at least one element of the prediction is unstable and we have difficulty in telling how the sequence will develop in the future.

Yet another difficulty arises from the fact that even if energy is currently building up in the form of deformation at the critical area, it is not at all necessary that a large earthquake will occur as soon as the activated system enters the critical state (at time $t_{c}$ ). The CP model merely predicts that past this time an earthquake is possible. As stated in the introduction, the time of the large event may depend on several uncertain factors pertaining to the nucleation process, which may have significant time dependence. Moreover, the stored energy may be dissipated with aseismic (low moment release rate) event(s) or with a series of smaller earthquakes. Again, the absence of a concrete case history complicates our ability to make solid inferences. For all the reasons above, and given the little experience with the method on the international level, it is hard to assert a prediction.

On the upside, we note that the results are based on a physical, not a statistical model. If it represents real Earth processes, then the evidence is telltale and compelling. Note also that if the prediction of CP theory is correct, that pre-shock magnitudes get progressively larger with approaching to failure, then recent seismicity patterns indicate that the critical point may not be far. To this effect, we note that Papazachos et al. (2002) have also made very similar observations and predictions for the same area, based on a quite different catalogue from which only magnitudes greater than 5 were used, by implementing a significantly different detection and estimation procedure. It appears that at this point in time, the only answer is continuous monitoring of seismicity changes, persistent vigilance for additional evidence that will signal the approach of the critical time and good luck, whatever is the meaning of "luck" in a situation like this! The bottomline is that we have detected and documented evidence of a self-organised fault network possibly working its way toward instability, which is strongly suggestive of a true physical process. If not, then we have probably come across a synod of truly diabolic coincidences! 


\section{References}

Allègre, C. J. and LeMouël, J. L.: Introduction of scaling techniques in brittle failure of rocks, Phys. Earth Planet Inter., 87, 85-93, 1994.

Ben-Zion, Y. and Lyakhovsky, V.: Accelerated seismic release and related aspects of seismicity patterns on earthquake faults, Pure Appl. Geophys., in press, 2002.

Bowman, D. D., Ouillon, G., Sammis, C. G., Sornette, A., and Sornette, D.: An observational test of the critical earthquake concept, J. Geophys. Res., 103, 24 359-24 372, 1998.

Bowman, D. D. and King, G. C. P.: Accelerating seismicity and stress accumulation before large earthquakes, Geophys. Res. Lett., 38 (21), 4039-4042, 2001.

Brehm, D. J. and Braile, L. W.: Application of the time-to-failure method for intermediate term prediction in the New Madrid Seismic Zone, Bull. Seism. Soc. Am., 88, 864-580, 1998.

Brehm, D. J. and Braile, L. W.: Intermediate term earthquake prediction using the modified time-to-failure method in Southern California, Bul. Seism. Soc. Am., 89, 275-293, 1999.

Bufe, C. G. and Varnes, D. J.: Predictive modelling of the seismic cycle of the greater San Francisco Bay region, J. Geophys. Res., 98, 9871-9883, 1993.

Bufe, C. G., Nishenko, S. P., and Varnes, D. J.: Seismicity trends and potential for large earthquakes in the Alaska-Aleutian region, Pure Appl. Geophys., 142, 83-99, 1994.

Dieterich, J. H.: Earthquake nucleation on faults with rate- and state-dependent strength, Tectonophysics, 211, 115-134, 1992.

Dieterich, J. A.: A constitutive law for earthquake production and its application to earthquake clustering, J. Geophys. Res., 99, 2601-2618, 1994.

Ferraes, S. G.: The Bayesian probabilistic prediction of strong earthquakes in the Hellenic Arc, Tectonophysics, 111, 339-354, 1985.

Gomberg, J. and Ellis, M.: Topography and tectonics and of the New Madrid seismic zone: Results of numerical experiments using a three-dimensional boundary element program, J. Geophys. Res., 99, 20 299-20310, 1994.

Gomberg, J. and Davis, S.: Stress/strain changes and triggered seismicity at The Geysers, California, J. Geophys. Res., 101, 733$750,1996$.

Gutenberg, B. and Richter, C. F.: The energy of earthquakes, Q. J. Geol. Soc. London, 112, 1-14, 1956.

Habermann, R. E.: Teleseismic detection in the Aleutian Island Arc, J. Geophys. Res., 88, 5056-5064, 1983.

Harris, R. A. and Simpson, R. W.: In the shadow of 1857 - Effect of the great Ft. Tejon earthquake on the subsequent earthquakes in southern California, Geophys. Res. Lett., 23, 229-232, 1996.

Heimpel, M.: Critical behaviour and the evolution of fault strength during earthquake cycles, Nature, 388, 865-868, 1997.

Hanks, T. C.: Earthquake stress drops, ambient tectonic stresses and stresses that derive plate motions, Pure Appl. Geophys., 115, 441-458, 1977.

Herrmann, H. J. and Roux, S. (Eds): Statistical Models for the Fracture of Disordered Media, 353 pp., Elsevier, Amsterdam, 1990.

Hill, D. P., Johnston, M. J. S., and Langbein, J. O.: Response of Long Valley caldera to the $M_{w}=7.3$ Landers, California earthquake, J. Geophys. Res., 100, 12 985-13 005, 1995.

Huang, Y., Saleur, H., Sammis, C. G., and Sornette, D.: Precursors, aftershocks, criticality and self-organized criticality, Europhys. Lett., 41, 43-48, 1998.

International Seismological Centre, On-line Bulletin, http://www.
isc.ac.uk/Bull, Internatl. Seis. Cent., Thatcham, UK, 2001.

Jaumé, S. C. and Sykes, L. R.: Evolving towards a critical point: A review of accelerating moment/energy release prior to large and great earthquakes, Pure Appl. Geophys., 155, 279-306, 1999.

Jones, L. and Haukson, E.: The seismic cycle in southern California: Precursor or response?, Geophys. Res. Lett., 24, 469-472, 1997.

Kanamori, H. and Anderson, D. L.: Theoretical basis of some empirical relations in seismology, Bull. Seismol. Soc. Am., 65, 1073-1095, 1975.

Keilis-Borok, V.: The lithosphere of the Earth as a large nonlinear system, in: Quo Vademus: Geophysics for the Next Generation, Geophys. Monogr. Ser., vol. 60. (Eds) Garland, G. D. and Apel, J. R., pp. 81-84, AGU, Washington, D.C., 1990.

King, G. C. P. and Bowman, D. D.: A physical model for seismicity during the earthquake cycle: Aftershocks, quiescence, and accelerating moment release, J. Geophys. Res., submitted, 2001.

Lyakhovsky, V., Ben-Zion, Y., and Agnon, A.: Distributed Damage, Faulting, and Friction, J. Geophys. Res., 102, 27 635-27 649, 1997.

Margaris, B. N. and Papazachos, C. B.: Moment-magnitude relations based on strong-motion records in Greece, Bull. Seism. Soc. Am., 89, 442-455, 1999.

Nalbant, S. S., Hubert, A., and King G. C. P.: Stress coupling between earthquakes in northwest Turkey and the north Aegean Sea, J. Geophys. Res., 103, 24 469-24 486, 1998.

Papadopoulos, T., Wyss, M., and Schmerge, D. L.: Earthquake locations in the western Hellenic Arc relative to the plate boundary, Bull. Seism. Soc. Amer., 78, 1222-1231, 1988.

Papadopoulos, G. A.: Long term earthquake prediction in the Western Hellenic arc, Earthquake Pred. Res., 4, 131-137, 1986.

Papadopoulos, G. A.: A note on the prediction of 13 September 1986 strong earthquake in Kalamata, south-west Peloponnesus, Greece, Tectonophysics, 145, 337-341, 1988a.

Papadopoulos, G. A.: Long-term accelerating foreshock activity may indicate the occurrence time of a strong shock in the Western Hellenic Arc, Tectonophysics, 152, 179-192, 1988 b.

Papazachos, B. C. and Comninakis, P. E.: Long-term earthquake prediction in the Hellenic arc-trench system, in: Geodynamics of the Hellenic Arc and Trench, (Eds) Le Pichon X., Augustithis S. S., and Mascle J., Tectonophysics, 86, 3-16, 1982.

Papazachos, B. C.: Seismicity of the Aegean and surrounding areas, Tectonophysics, 178, 287-308, 1990.

Papazachos, B. C. and Papazachou, C. C.: Earthquakes of Greece, Ziti publ. Thessaloniki, 304 pp., 1997.

Papazachos, B. C., Kiratzi, A. A., and Karakostas, B. G.: Toward a homogeneous moment-magnitude determination for earthquakes in Greece and the surrounding area, Bull. Seism. Soc. Am., 87, 474-483, 1997.

Papazachos, B. C. and Papazachos, C. B.: Accelerated preshock deformation of broad areas in the Aegean area, Pure appl. Geophys., 157, 1663-1681, 2000.

Papazachos, C. B. and Papazachos, B. C.: Precursory accelerated Benioff strain in the Aegean area, Ann. Geofisica, 144, 461-474, 2001.

Papazachos, C. B, Karakaisis, G. F., Savvaidis, A. S., and Papazachos, B. C.: Accelerating seismic crustal deformation in the Southern Aegean area, Bull. Seism. Soc. Am., 92, 570-580, 2002.

Reasenberg, P. A.: Second-order moment of Central California Seismicity, 1969-1982, J. Geophys. Res., 90, 5479-5495, 1985.

Reasenberg, P. A. and Simpson, R. W.: Response of regional seis- 
micity to the static stress change produced by the Loma Prieta earthquake, Science, 255, 1687-1690, 1992.

Rundle, J. B., Klein, W., Turcotte, D. L., and Malaud, B. D.: Precursory seismic activation and critical point phenomena, Pure Appl. Geophys., 157, 2165-2182, 2000.

Saleur, H., Sammis, C. G., and Sornctte, D.: Renormalization group theory of earthquakes, Non. Proc. Geophys., 3, 102-109, 1996 a.

Saleur, H., Sammis, C. G., and Sornette, D.: Discrete scale invariance, complex fractal dimensions, and log-periodic fluctuations in seismicity, J. Geophys. Res., 101, 17 661-17 677, 1996 b.

Sammis, C. G. and Sornette, D.: Positive feedback, memory and the predictability of earthquakes, e-print at http://arXiv.org/abs/ cond-mat/0107143v1, July 2001.

Sornette, D., Vanneste, C., and Knopoff, L.: Statistical model of earthquake foreshocks, Phys. Rev. A, 45, 8351-8357, 1992.

Sornette, D. and Sammis, C. G.: Complex critical exponents from renormalization group theory of earthquakes: Implications for earthquake predictions, J. Phys. 1, 5, 607-619, 1995.

Stein, R. S., Barka, A. A., and Dieterich, J. H.: Progressive fail- ure on the North Anatolian fault since 1939 by earthquake stress triggering, Geophys. J. Int., 128, 594-604, 1997.

Toda, S. R., Stein, R. S., Reasenberg, P. A., Dieterich, J. H., and Yoshida, A.: Stress transferred by the $1995 M_{w}=6.9$ Kobe, Japan shock: Effect on aftershocks and future earthquake probabilities, J. Geophys. Res., 103, 24 543-24 566, 1998.

Vanneste, C. and Sornette, D.: Dynamics of rupture in thermal fuse models, J. Phys. I Fr. 2, 1621-1644, 1992.

Varnes, D. J.: Predicting earthquakes by analysing accelerating precursory seismic activity, PAGEOPH, 130, 661-686, 1989.

Voight, B.: A relationship to describe rate-dependent material failure, Science, 243, 200-203, 1989.

Wyss, M. and Baer, M.: Seismic quiescence in the western Hellenic arc may foreshadow large earthquakes, Nature, 289, 785-787, 1981.

Zúñiga, F. R. and Wyss, M.: Inadvertent changes in magnitude reported in earthquake catalogs: Their evaluation through b-value estimates, Bull Seismol. Soc. Am., 85, 1858-1866, 1995. 